\title{
Malawi health workers grapple with rising incidence of rape
}

Published at www.cmaj.ca on Oct. 22

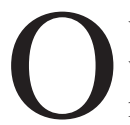
ver the past few years, health workers in Malawi have noticed an unforeseen consequence of the availability of free antiretrovirals: more rape victims are showing up in hospitals.

Since 2005, when the Global Fund began providing AIDS drugs to the country, word has been spreading that Post Exposure Prophylaxis, a 30-day preventative combination of medications, is on hand for HIV-negative rape victims at health centres. Most effective within 36 hours after exposure, the 30day dosage of antiretroviral medication can be initiated up to 72 hours after potential contact with the virus.

"The communities are becoming aware that PEP (post-exposure prophylaxix) is available and more people are reporting rape to health centres because of it," says Prisca Masepuka, a reproductive health officer at Malawi's Ministry of Health. In one hospital, Kamuzu Central, the number of patients reporting an assault increased from 78 for the year 2006-2007 to 134 patients for 2007-2008.

But in a country with a doctorpatient ratio of 1 to 100 000, Malawi's health system is struggling to handle the upsurge. After all, rape victims need more than post-exposure prophylaxis. They require counselling, emergency contraception, a medical examination to serve as evidence and, in some cases, a safe place to stay.

In response to the growing challenge, Malawian health care workers, police, justice officials and civil society members gathered for a three-day workshop in late September to try to lay out a coordinated and standardized response protocol for sexual assault victims.

The workshop, held in the mountainous town of Zomba in southern Malawi, was hosted by the Canadian organization Dignitas International, which works in collaboration with the health ministry to prevent the spread

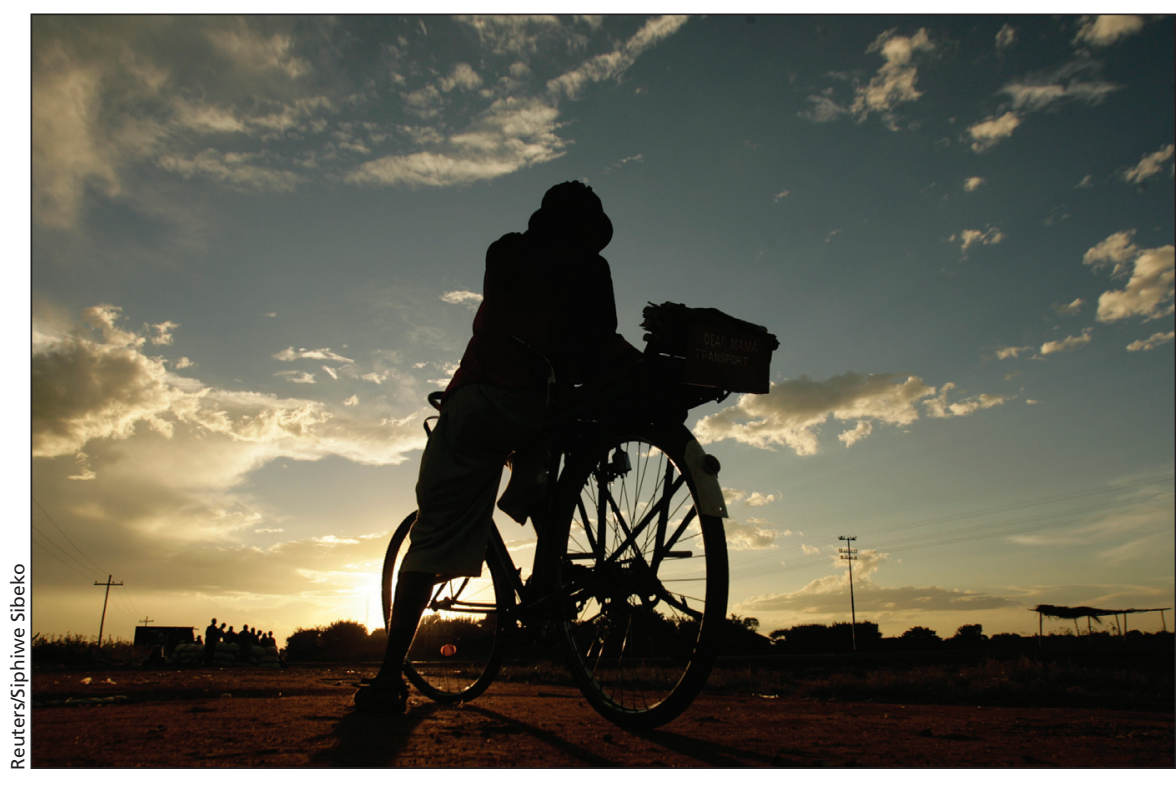

Bicycles are a common and cheap form of transportation for many rural residents in Malawi, but the cost of travelling to urban hospitals for treatment is still prohibitory for impoverished rape victims.

of HIV, as well as scale up and decentralize AIDS treatment.

In most developed countries, a team of crisis professionals is often called in to counsel, treat and protect a rape victim, especially when the victim is a child.

But in Malawi, victims and their families are expected to access psychosocial, legal and health services on their own. Many are unaware of the services and face the additional burden of transport costs - for the average Malawian, a trip from the village to an urban area can cost a week's salary.

"You actually see from their faces how traumatized these patients are, but I don't have the training to provide counselling so I just provide medical care," says Esau Munthalo, a clinical officer at one of Malawi's four central hospitals, who treats about one sexual assault victim a month, some below age 10. (In Malawi, clinical officers have four years of training and perform many duties of physicians.)

Hoping to encourage health workers at the workshop to step beyond their medical roles, pediatrician Dr. Neil
Kennedy waved his cellphone in the air. "Use one of these — God's greatest gift to Malawi," he said. "Call the social workers. Make sure the child is safe to go home. We've kept children at our hospital for three days because we didn't think they were going back to a safe situation."

Such coordinated responses will help victims access the care they need, Kennedy says. Still, there's an urgent need for senior staff in Malawi's 28 district hospitals to undergo rigorous training in the medical, legal and psychosocial aspects of gender-based violence, he added. If that were to happen, patients need travel no more than 20 kilometres by bicycle taxi to their district hospital to receive care, rather than face a prohibitively expensive, 80-kilometre trip to an urban hospital.

Health providers outside of Malawi's four central hospitals frequently lack the experience to discern the signs of genital tract trauma in children, Kennedy says, adding that, as a result, they could impede justice by unjustifiably claiming that a rape hasn't occurred and are more 
likely to recant under grilling from a defence lawyer.

Many health workers also haven't been adequately educated about the laws surrounding rape. Several conference attendees were surprised to hear that the rape of a child under 13 must be reported to the police, irrespective of family wishes.

Poverty can also be a factor. Women often have no option but to place themselves in perilous situations, such as relying on strangers for transport or walking long distances in remote areas. When children are raped, it often happens when a parent or guardian has gone to collect firewood or tend fields, leaving the child alone or with an untrustworthy neighbour, Kennedy said.

Munthalo says that in other instances, the accused "may be the source of income for the family. If he is put in jail for years, the whole family suffers."

Health care workers have a huge role to play as advocates for the abused, Kennedy said, citing as an example, an instance in which a child who was brought to a clinic said that a man had lain on top of her and "urinated" on her. The child's description of the urine matched that of ejaculate. Yet when Kennedy went to the police, they informed him that nothing could be done because penetration hadn't occurred. Kennedy said the police officer was finally persuaded to lay an aggravated assault charge and the perpetrator was eventually sentenced to two years in prison. "It's not optimal but it's something," Kennedy said.

Grim as the situation appears, Kennedy says there's been progress in the largely Christian and conservative nation since he arrived from Ireland. After all, Malawi was ruled for three decades by Hastings Banda, a dictator who decreed women were not permitted to wear skirts cut above the knee.

"When I came here in the late 1990s, I asked doctors what they do in cases of child sexual abuse. I was told, 'We don't have that here. That's something that only happens in azungu-land'," said Kennedy, using the local term for Caucasian. "It's the same attitude we had in Ireland 30 or 40 years ago. It's going to be an incremental process." - Wendy Glauser, Zomba, Malawi

Funding: Wendy Glauser is supported by a Canadian Institutes of Health Research journalism grant.

DOI:10.1503/cmaj.109-3087 